\title{
A simplified model to predict diurnal water temperature dynamics in a shallow tropical water pool
}

\author{
Krijn P. Paaijmans • Bert G. Heusinkveld • \\ Adrie F. G. Jacobs
}

Received: 8 February 2008 /Revised: 24 April 2008 / Accepted: 9 June 2008 / Published online: 15 July 2008

(C) The Author(s) 2008

\begin{abstract}
Water temperature is a critical regulator in the growth and development of malaria mosquito immatures, as they are poikilothermic. Measuring or estimating the diurnal temperature ranges to which these immatures are exposed is of the utmost importance, as these immatures will develop into adults that can transmit malaria. Recent attempts to predict the daily water temperature dynamics in mosquito breeding sites in Kenya have been successful. However, the developed model may be too complex, as the sophisticated equipment that was used for detailed meteorological observations is not widely distributed in Africa, making it difficult to predict the daily water temperature dynamics on a local scale. Therefore, we compared two energy budget models with earlier made observations of the daily water temperature dynamics in a small, shallow and clear water pool (diameter $0.96 \mathrm{~m}$, depth $0.32 \mathrm{~m}$ ) in Kenya. This paper describes (1) a complex 1-Dimensional model, and (2) a simplified second model, and (3) shows that both models mimic the water temperature dynamics in the water pool accurately. The latter model has the advantage that it only needs common weather data (air temperature, air
\end{abstract}

K. P. Paaijmans • B. G. Heusinkveld • A. F. G. Jacobs

Meteorology and Air Quality, Wageningen University,

Wageningen, The Netherlands

K. P. Paaijmans

Laboratory of Entomology, Wageningen University,

Wageningen, The Netherlands

Present address:

K. P. Paaijmans $(\varangle)$

Center for Infectious Disease Dynamics/Entomology Department,

Pennsylvania State University,

19A Chemical Ecology Lab,

University Park, PA 16802, USA

e-mail: krijn@paaijmans.nl humidity, wind speed and cloud cover) to estimate the diurnal temperature dynamics in breeding sites of African malaria mosquitoes.

Keywords Shallow water body . Water temperature . Common weather data . Energy budget $\cdot$ Model simulations . Malaria mosquito larvae

\section{Introduction}

Climate plays a major role in the distribution and abundance of insect species (Andrewartha and Birch 1954; Sutherst et al. 1995). As insects are poikilothermic, their growth and development rates are strongly affected by the temperature of their direct environment. In general, within a certain temperature range, insects experience an increased growth rate at higher temperatures (Atkinson 1994). This temperature dependency applies to the immatures of mosquitoes that transmit malaria as well: The growth and development rates of larvae of the Anopheles gambiae complex, known as the most important vector species of malaria in sub-Saharan Africa, are temperaturedependent (Lyimo et al. 1992; Bayoh and Lindsay 2003). The larvae live close to the water surface in shallow waters, such as borrow pits, road puddles, tire tracks and animal hoof prints, and are exposed to considerably diurnal variations in water temperature (Jepson et al. 1947; Huang et al. 2006; Paaijmans et al. 2008a).

Information about the actual diurnal water temperature dynamics, combined with information on insect growth and development in relation to water temperature and initial larval densities, would enable us to predict the growth of malaria vector populations. However, there is little available detailed information on the diurnal water temperature 
dynamics of aquatic breeding sites, and so current epidemiological models use, by necessity, data on adult mosquitoes although the population size of these insects is significantly determined by the development and survival in the aquatic stage (Service 1993). Therefore, fundamental studies that assess the effects of abiotic processes on aquatic processes are needed.

A few detailed one-dimensional water temperature models are described in the literature that estimate the diurnal temperature dynamics in small water bodies (Losordo and Piedrahita 1991; Jacobs et al. 1997; Jacobs et al. 1998; Jacobs et al. 2008; Paaijmans et al. 2008a). However, these models require a lot of detailed meteorological input variables, such as air temperature, air humidity, precipitation, wind speed, incoming shortwave and longwave radiation and soil heat flux. In sub-Saharan Africa, where over $80 \%$ of malaria deaths occur (WHO 2005), good and accurate equipment for meteorological measurements are scarce or meteorological stations measure only basic variables, such as wind speed, air temperature, air humidity and precipitation. Therefore, a simplification of current models by, e.g., including estimations of incoming radiation and of the soil heat flux, may prove useful here. If a simplified model was available that only requires basic meteorological input variables, the daily average water temperature and its extremes can be estimated, providing a window for modelers who try to predict the immature and, consequently, adult mosquito population dynamics. This will subsequently improve current malaria risk models.

The objectives of the present study are: (1) to test whether a 1-dimensional model can be used to predict the observed diurnal water temperature dynamics in a tropical shallow water pool, and (2) to test if a simplified atmosphere-water model, using common measured weather data as input variables, is also able to simulate these dynamics.

\section{Materials and methods}

Observations of the water temperature dynamics

Experiments were carried out in Kenya at the Kenya Medical Research Institute (KEMRI) near Kisumu $\left(0^{\circ} 04^{\prime} 36.390^{\prime \prime S}, 34^{\circ} 40^{\prime} 34.770\right.$ ”E; $1,126 \mathrm{~m}$ a.s.l.). In a circular pool (diameter $0.96 \mathrm{~m}$, depth $0.33 \mathrm{~m}$ ) that was filled with clear tap water to within $10 \mathrm{~mm}$ of the brim, the diurnal water temperature was measured with glass bead thermometers (NTC BEAD 4K7; Thermometrics USA) at various depths $(1,30,60120$ and $240 \mathrm{~mm})$. The water pool was lined with semi-transparent plastic $(0.13 \mathrm{~mm})$, pressed tightly against the soil to maximize plastic-soil contact. At the bottom of the water pool, a soil heat flux plate was installed (Type WS 31-Cp; TNO, The Netherlands) between the plastic and the soil. Soil temperatures were measured with similar thermistors at $0.05,0.17$ and $0.33 \mathrm{~m}$ depths in the undisturbed soil.

At a nearby weather station, wind speed at heights of 2 and $10 \mathrm{~m}$ were measured with cup anemometers (Meteorology and Air Quality, Wageningen University) and the air temperature and relative humidity with a ventilated probe (Vaisala, Finland) at $2 \mathrm{~m}$ height. Precipitation was measured with a tipping bucket rain gauge (Eijkelkamp, Netherlands). Incoming shortwave and longwave radiation were measured at $1.5 \mathrm{~m}$ height with a pyranometer and pyrgeometer, respectively (Type CM11 and CG1, respectively; Kipp \& Zonen, Netherlands).

The data were totaled (rain) or averaged (remaining variables) over $15 \mathrm{~min}$ and stored on a datalogger (Type 21×; Campbell Scientific, U.K.). More detailed information about the set-up and data processing can be found in Paaijmans et al. (2008a). For the purpose of this study, a period of three consecutive days (28 February to 2 March 2005) was selected to analyze the processes taking place within the water pool and to verify both water temperature models. This period experienced predominantly clear sky conditions, which was required to validate the simplified model, as no cloud-cover readings were carried out during the study period.

\section{Model 1: One-layer energy budget model}

Complex 1-dimensional models to simulate the water temperature of shallow water bodies are available and details of such models can be found elsewhere (Jacobs et al. 1997, 2008). As our results showed that the small water pool in Kenya was homothermic (see Paaijmans et al. 2008a), the water pool temperature can be simulated with a simple one-layer energy budget model. This model is briefly described below.

The energy budget of a homogeneous water pool can be described by the energy budget:

$$
\begin{aligned}
& K_{\text {in }}\left(1-\alpha_{t}\right)+L_{\text {in }}+P-L_{\text {out }}-H-L E-G_{s} \\
& \quad=\rho_{w} c_{w} \delta \frac{\Delta T_{w}}{\Delta t}
\end{aligned}
$$

where $K_{\text {in }}\left(\mathrm{W} \mathrm{m}^{-2}\right)$ is the incoming shortwave radiation, $\alpha_{t}(-)$ is the total albedo of the water pool, $L_{\text {in }}\left(\mathrm{W} \mathrm{m}^{-2}\right)$ the incoming longwave radiation, $P\left(\mathrm{~W} \mathrm{~m}^{-2}\right)$ the energy that is transferred advectively by precipitation, $L_{\text {out }}\left(\mathrm{W} \mathrm{m}^{-2}\right)$ the outgoing longwave radiation at the water surface, $H\left(\mathrm{~W} \mathrm{~m}^{-2}\right)$ the sensible heat exchange at the water surface, $L E\left(\mathrm{~W} \mathrm{~m}^{-2}\right)$ the evaporation at the water surface, $G_{s}\left(\mathrm{~W} \mathrm{~m}^{-2}\right)$ the conduction heat exchange at the bottom and the side walls 
of the water pool, $\rho_{w}\left(\mathrm{~kg} \mathrm{~m}^{-3}\right)$ the density of water, $c_{w}$ $\left(\mathrm{J} \mathrm{kg}^{-1} \mathrm{~K}^{-1}\right)$ the heat capacity of the water, $\delta(\mathrm{m})$ the depth of the water pool, $T_{w}\left({ }^{\circ} \mathrm{C}\right)$ the temperature of the water pool, and $t(\mathrm{~s})$ is time.

The albedo for deep water is $\alpha_{d w}=0.08$ (Weast 1984). For shallow and clear water, with no radiative absorption within the water pool, the albedo, $\alpha_{s w}$, is:

$\alpha_{s w}=\alpha_{d w}+\left(1-\alpha_{d w}\right)(1-\beta) \alpha_{b}$

where $\alpha_{b}(-)$ is the albedo of the bottom of the water pool with the numerical value $\alpha_{b}=0.13$ (Campbell and Norman 2000) and $\beta(-)$ the near infrared fraction of the incoming shortwave radiation that is absorbed in a thin water layer at the water-atmosphere interface, which has a numerical value of $\beta=0.45$ (Orlob 1983). In our case, this means that the total albedo of the water pool $\alpha_{t} \leq \alpha_{s w}$, as some absorption will takes place within the water pool. In the present study, by fitting optimization, a numerical value of $\alpha_{t}=0.15$ is used. The outgoing longwave radiation is parameterized by:

$L_{\text {out }}=\varepsilon_{w} \sigma T_{w}^{4}$

where $\varepsilon_{w}(-)$ is the emissivity of water with a value of 0.98 (Weast 1984), $\sigma\left(=5.6710^{-8} \mathrm{~W} \mathrm{~m}^{-2} \mathrm{~K}^{-4}\right)$ the Stefan Boltzmann's constant and $T_{w}(\mathrm{~K})$ the absolute water temperature. The sensible heat flux, $H$, is parameterized by (Arya 2001):

$H=\rho_{a} c_{p} u C_{h}\left(T_{w}-T_{a}\right)$

where $\rho_{a}\left(\mathrm{~kg} \mathrm{~m}^{-3}\right)$ is the density of air, $c_{p}\left(\mathrm{~J} \mathrm{~kg}^{-1} \mathrm{~K}^{-1}\right)$ the heat capacity of air, $u\left(\mathrm{~m} \mathrm{~s}^{-1}\right)$ the wind speed at a reference height of $2.0 \mathrm{~m}, C_{h}(-)$ the dimensionless heat transfer coefficient at the reference height with a numerical value of $C_{h}=3 \cdot 10^{-3}$ (Paaijmans et al. 2008a), and $T_{a}\left({ }^{\circ} \mathrm{C}\right)$ the air temperature. The evaporation flux, $L E$, is parameterized by (Arya 2001):

$L E=\rho_{a} \lambda u C_{e}\left(q_{w}-q_{a}\right)$

where $\lambda\left(\mathrm{J} \mathrm{kg}^{-1}\right)$ is latent heat for vaporization, $C_{e}(-)$ the dimensionless mass transfer coefficient at reference height with a numerical value of $C_{e}=C_{h}, q_{w}\left(\mathrm{~kg} \mathrm{~kg}^{-1}\right)$ the specific moisture content at the water surface and $q_{a}\left(\mathrm{~kg} \mathrm{~kg}^{-1}\right)$ the specific moisture content at reference height.

Energy may also be transferred advectively by precipitation due to a difference in temperature between the water pool and the rain droplets. This was calculated by:

$P=\frac{\rho_{w} c_{w} r_{a}\left(T_{r}-T_{w}\right)}{\Delta t}$

where $r_{a}$ is the amount of precipitation $(\mathrm{m})$ and $T_{r}(\mathrm{~K})$ the temperature of the rain drops. $T_{r}$ was assumed to be equal to the wet bulb temperature and was estimated according to Jensen et al. (1990).
The soil heat flux is corrected for heat transport through the side wall by:

$G_{s}=G\left(1+\frac{2 \pi r \delta}{A}\right)$

where $\left.G(\mathrm{~W} \mathrm{~m})^{-2}\right)$ is the measured soil heat flux at the bottom of the water pool, $r(\mathrm{~m})$ the radius and $A\left(\mathrm{~m}^{2}\right)$ the surface of the water pool. Here, it is assumed that the mean soil heat flux density at the sides is similar to the soil heat flux density at the bottom.

Equation (1) can easily be integrated, which will give the homogeneous temperature of the water pool (Model 1).

Model 2: a simplification of model 1

Our next model (model 2) is similar to model 1, but the incoming radiation terms, $K_{\text {in }}$ and $L_{i n}$, and the soil heat flux term, $G_{s}$, are simply parameterized. When the exact geographic location of a place is known, the so-called Angot incoming radiation, $R_{o}$, can be calculated, which is the incoming shortwave radiation at the edge of the atmosphere (Iqbal 1984; Stull 2000). Applying Ångström’s formula, we find the incoming shortwave radiation, $K_{i n}$, at the earth's surface (Ångström 1924):

$K_{\text {in }}=R_{o}\left(0.20+0.55\left(1-m_{c}\right)\right)$

where $m_{c}$ is the proportion of the sky covered by clouds. The incoming longwave radiation is parameterized by (Brunt 1932; Brutsaert 1982):

$L_{i n}=(0.56+0.067 \sqrt{e}) \sigma T_{a}^{4}+d m_{c}$

where $e(\mathrm{hPa})$ is the vapor pressure at the reference height and $d$ is a constant (low clouds: $d=60 \mathrm{~W} \mathrm{~m}^{-2}$, and high clouds: $d=30 \mathrm{~W} \mathrm{~m}^{-2}$ ).

The vapor pressure at reference height, $e$, is estimated using the Clausius-Clapeyron equation (Stull 2000) for the saturated vapor pressure, $e_{s}$ :

$e_{s}=611.2 \exp \left(\frac{17.67 T_{a}}{T_{a}+243.5}\right)$

where $T_{a}$ is the air temperature in degrees Celcius, and next:

$e=R H \cdot e_{s}$

where $R H$ is relative humidity in parts.

The soil heat flux, $G_{s}$, is estimated with (Garratt 1992):

$G_{S}=0.15 R_{\text {net }}=0.15\left(K_{\text {in }}\left(1-a_{t}\right)+L_{\text {in }}-L_{\text {out }}\right)$

where $R_{\text {net }}\left(\mathrm{W} \mathrm{m}^{-2}\right)$ is the amount of net radiation and the factor 0.15 is estimated by optimization. 


\section{Results and discussion}

The observed water temperatures at various depths, the air temperature and the undisturbed soil temperature at $50 \mathrm{~mm}$ are depicted in Fig. 1. From the result in Fig. 1, we infer that the water pool shows a more or less homogeneous diurnal water temperature behavior and that the application of a homogeneous water temperature model is justified. However, the water temperature near the air-water interface (measured at $2 \mathrm{~mm}$ below the interface) is somewhat lower than that of the deeper layers. This is attributed to the evaporation at the air-water interface, which attracts latent energy for vaporization from the top water layer of the water pool. This effect is also observed in large water bodies, such as the North Sea (Jacobs et al. 1999). It is furthermore concluded from Fig. 1 that the water temperature is higher than the air temperature for most parts of the days. This means that the sensible heat flux is predominantly from the water pool towards the atmosphere during both day- and nighttime. Moreover, this temperature difference will cause a continuous vaporization of water. Finally, Fig. 2 shows that the undisturbed soil temperature at $50 \mathrm{~mm}$ depth is higher than the water temperatures during daytime while the opposite occurs during nighttime. This will result in a soil heat flux towards the water pool during daytime whereas the opposite occurs during nighttime. This will be shown below.

The upper panel of Fig. 2 shows the meteorological conditions during the selected study period and the lower panel the observed water temperature dynamics as well as the water temperature dynamics that are simulated by model 1. The figure shows that rainfall hardly has an effect on the water temperature. This is anticipated: e.g., a rain event with $1 \mathrm{~mm}$ precipitation in $900 \mathrm{~s}$ corresponds with an

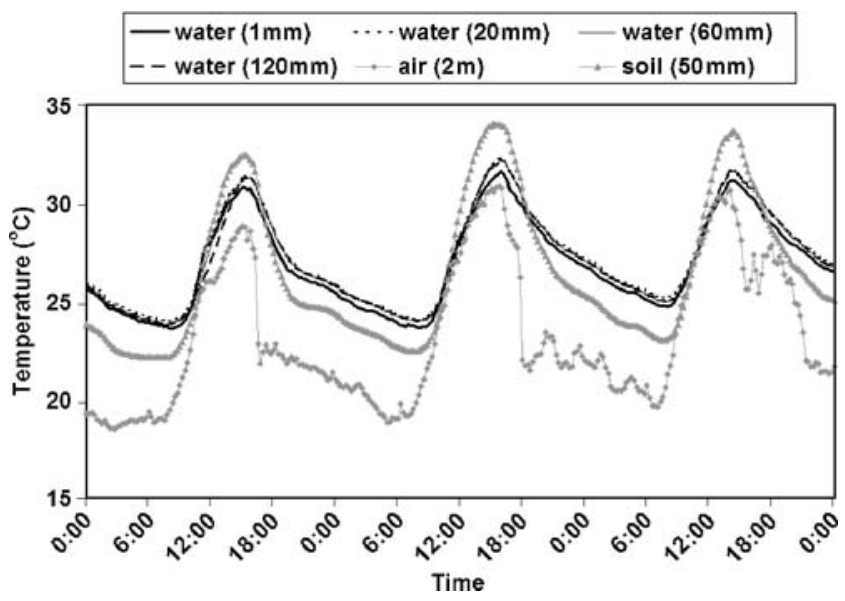

Fig. 1 The diurnal water temperature dynamics of a tropical water pool, measured at various depths for three consecutive days (28 Feb to 2 March 2005). Air temperature at $2 \mathrm{~m}$ above ground and the temperature of the undisturbed soil at a depth of $50 \mathrm{~mm}$ are plotted energy flux of approximately $5 \mathrm{~W} \mathrm{~m}^{-2}$ if there is a temperature difference of $5 \mathrm{~K}$ between the rain drops and water pool (equation 6). The heat capacity of our water pool is approximately $1.310^{6} \mathrm{~J} \mathrm{~m}^{-2} \mathrm{~K}^{-1}$, which is very high and hence reduces the effect of rain on the water temperatures. The same result was found earlier by Evans et al. (1998.) in a river study. However, in a recent study on smaller water puddles, we found a noticeable effect of rain events on the water temperature (Paaijmans et al. 2008a).

Figure 3 contains the most important energy fluxes at the interfaces of the water pool. In Fig. 3, all positive terms are energy gains for the water pool while all negative terms are energy losses. $R_{n e t}$ is the net radiation at the water-air interface; the sum of the net shortwave and net longwave radiation fluxes. During daytime, $R_{n e t}$ is the most important input energy flux, while during nighttime, $R_{\text {net }}$ is a cooling term and is of the same order of magnitude as the evaporation term, $L E$. As mentioned previously, $L E$ is a

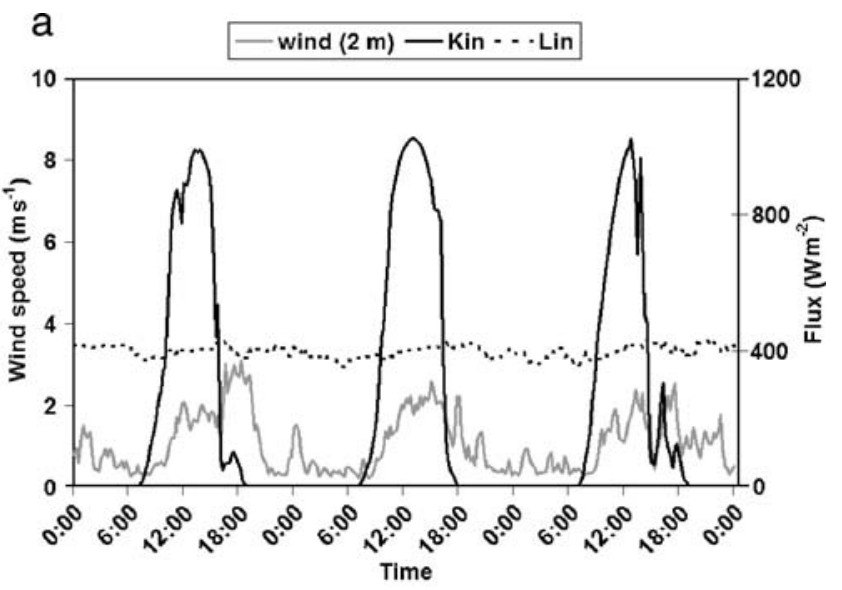

b

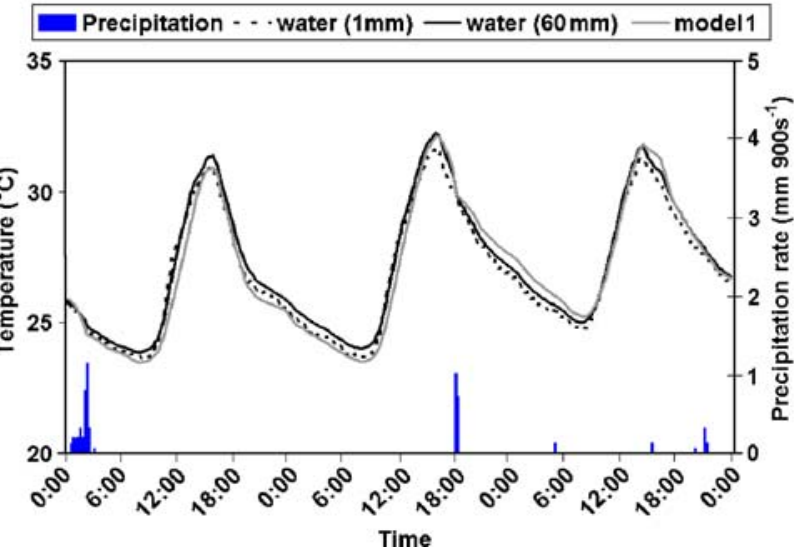

Fig. 2 Top panel The diurnal course of the incoming shortwave $\left(K_{i n}\right)$ and longwave $\left(L_{i n}\right)$ radiation and of the wind speed during the three selected consecutive days (28 Feb to 2 March 2005). Bottom panel The observed (at 1 and $60 \mathrm{~mm}$ below the air-water interface) and modeled (model 1) diurnal water temperature dynamics in a tropical water pool during the same three consecutive days. Precipitation is also depicted 


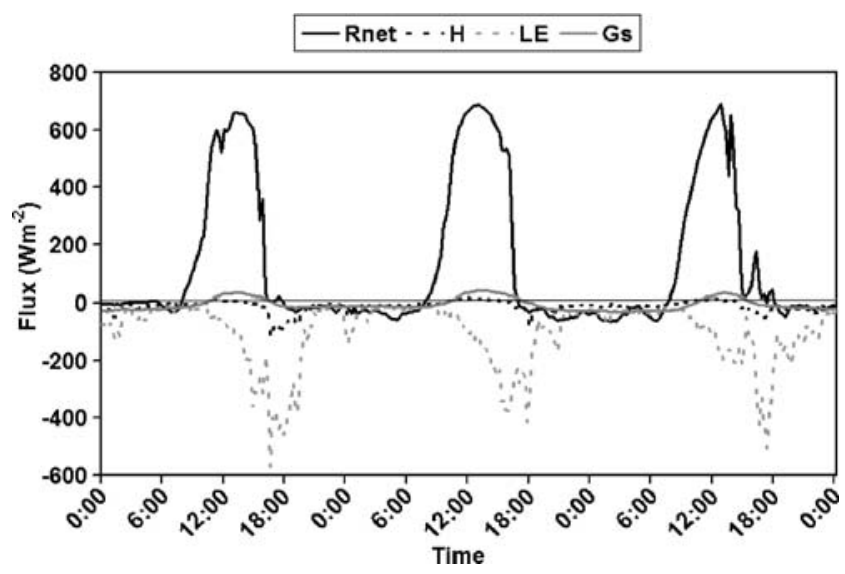

Fig. 3 Energy gains and losses at the water-atmosphere interface $\left(R_{n e t}\right.$ amount of net radiation; $H$ sensible heat flux; $L E$ latent heat flux) and at the water-soil interface $\left(G_{s}\right.$; the soil heat flux) of the water pool during 28 February to 2 March 2005 . Values above $0 \mathrm{~W} \mathrm{~m}^{-2}$ indicate energy gains and those below $0 \mathrm{~W} \mathrm{~m}^{-2}$ energy losses

cooling term throughout the day, which means that the vapor pressure at the air-water interface is always higher than the vapor pressure of the ambient air. We also conclude from Fig. 3 that the sensible heat flux is a relatively small energy loss term at the water-air interface. Only at occasional periods during the middle of the day does this term appear to be a small heating term. Finally, we infer from Fig. 3 that the soil heat flux is indeed an energy gain term during nighttime and a loss term during daytime, as is suggested above.

The most important forcing terms are the incoming shortwave and longwave radiation, $K_{i n}$ and $L_{i n}$, respectively. If these forcing terms are correctly estimated, it must be expected that the simplified model (model 2) will also simulate the water temperature dynamics accurately. Figure 4 contains a comparison between the measured incoming radiation fluxes and the modeled radiation fluxes (Eqs. 8 and 9). From Fig. 4, we conclude that the model mimics

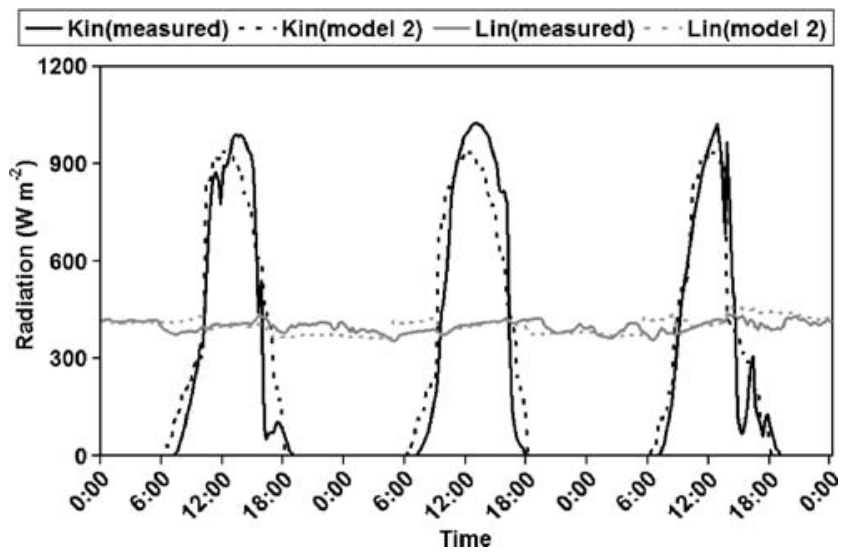

Fig. 4 Observed (solid lines) and estimated (dashed lines) incoming shortwave $\left(K_{i n}\right)$ and longwave $\left(L_{i n}\right)$ radiation during three consecutive days (28 February to 2 March 2005) with predominantly clear skies the observed radiation terms reasonably well. As cloud cover was not monitored during our outdoor experiments, we expect that the performance of the model will improve when cloud cover observations are carried out. It must be noted that, at low solar heights, until approximately a solar height of $30^{\circ}$, the direct solar radiation is interrupted by nearby vegetation and other obstructions. To mimic this effect, complete cloudiness is assumed at solar heights below $30^{\circ}$. Figure 5 shows the diurnal water temperature dynamics that are estimated with model 2 . We conclude that our simplified model mimics the water temperature observations nearly as well as the more detailed model (model 1), although the temperature extremes, during both daytime and nighttime, are underestimated by about $2 \mathrm{~K}$.

Currently, there are two limitations to our models. First, mosquito immatures are often found in turbid water pools and an increase in water turbidity may result in an increase in water temperature (Paaijmans et al. 2008b). Unfortunately, water turbidity is not an easy parameter to include in our models, as different levels of turbidity will have a different effect on the water temperature. However, changing the albedo (Eq. 2) may be a simple step to include water turbidity, as suspended particles in a water column absorb and scatter sunlight and hence determine the extinction of solar radiation. The albedo-value of turbid water will range from 0.08 to $\sim 0.14$, depending on the level of turbidity. The value for clear water is 0.14 (this paper), which may differ slightly, depending on the reflection by the soil at the soilwater interface. When water turbidity is maximal, an albedo of 0.08 may be used, which is the albedo for deep water. Whether a linear interpolation between these two albedovalues may provide us with a simple estimation of the albedo at any given turbidity needs to be studied in detail.

Second, the effect of water runoff is not included in the models. Apart from the creation of mosquito breeding sites by rainfall, which fills holes and other types of depressions,

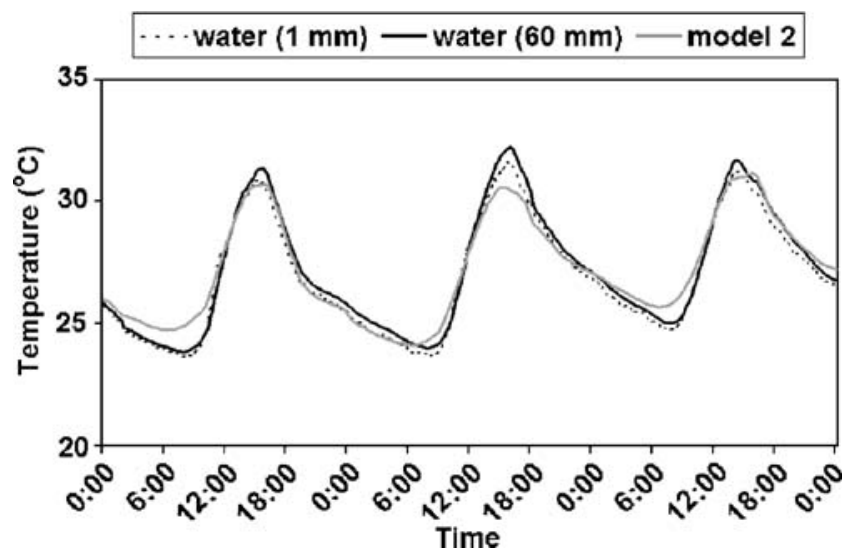

Fig. 5 The observed (at 1 and $60 \mathrm{~mm}$ below the air-water interface) and modeled (model 2) diurnal water temperature dynamics in a tropical water pool during three consecutive days (28 February to 2 March 2005) 
breeding sites will be formed by water runoff in such depressions. There are two possible scenarios, depending on the initial state of a water pool: (case 1) a water pool is newly formed, which means a different initial water temperature has to be applied in our model; and (case 2) water runoff fills an existing pool, which results in the mixing of the water in the pool with water that flows in. To model these scenarios accurately, one has to solve the energy budget equation of a vegetated or bare surface (depending on land cover; required for case 1 and 2) parallel to the water energy budget equation (case 2 only). To keep things simple, which is the intention of this paper, an adequate first guess of the initial water temperature is to take the air temperature just above the surface (e.g., $10 \mathrm{~cm}$ ) when the area is vegetated, or to use the soil temperature (e.g., at $1 \mathrm{~cm}$ depth) when the surface is bare or when vegetation is sparse. In the second scenario, a ratio of water pool volume:runoff volume has to be included to predict the impact of runoff on the current water temperature accurately. Both scenarios should be studied in more detail.

We conclude that water temperature dynamics in tropical, small and clear water bodies, can be estimated accurately with meteorological variables collected at common meteorological weather stations. However, it must be noted that the selected days in this study were relatively cloudless. For cloudy days, cloud cover observations are required to correct for the effects of clouds on both the incoming shortwave and incoming longwave radiation. These cloud observations can be carried out by an observer, but nowadays satellite images are available and can be applied for this purpose. Further studies are required to test this model under various climatic conditions. However, we are convinced this simplified model hands an opportunity to predict the diurnal water temperature dynamics in tropical water pools on a local scale, and may therefore contribute to better predictions of the abundance and distribution of malaria mosquitoes.

\section{Conclusions}

From the foregoing results and discussion, the following main conclusions can be drawn:

1. The water temperature of a small, clear water pool behaves more or less homogeneously over depth. Only the temperature of the thin layer near the air-water interface is somewhat lower due to evaporative energy losses.

2. The water temperature is nearly always higher than the air temperature at the reference height, which results in an almost continuous upward sensible heat flux and evaporation.

3. Rain events do affect the air temperature, but hardly affect the water temperature.
4. With a relatively simple one-layer energy budget model the homogeneous water temperature dynamics can be simulated accurately. However, to apply the model, the incoming shortwave and longwave radiation fluxes as well as the soil heat flux at the bottom and sides of the water pool are required.

5. The incoming shortwave and longwave radiation fluxes can be estimated with the Angot-Ångström concept and the Brunt formula, respectively. By also equating the soil heat flux with a percentage of the net radiation, only air temperature, air humidity, wind speed and the local cloud cover are required to model the diurnal water temperature dynamics in small, clear and tropical water pools.

Open Access This article is distributed under the terms of the Creative Commons Attribution Noncommercial License which permits any noncommercial use, distribution, and reproduction in any medium, provided the original author(s) and source are credited.

\section{References}

Andrewartha HG, Birch LC (eds) (1954) The distribution and abundance of animals. University of Chicago Press, Chicago

Ångström A (1924) Solar and terrestrial radiation. Q J R Meteorol Soc $50: 121-125$

Arya SP (eds) (2001) Introduction to micrometeorology. Academic Press, London

Atkinson D (1994) Temperature and organism size: a biological law for ectotherms. Adv Ecol Res 25:1-58

Bayoh MN, Lindsay SW (2003) Effect of temperature on the development of the aquatic stages of Anopheles gambiae sensu stricto (Diptera: Culicidae). Bull Entomol Res 93:375-381, doi:10.1079/BER2003259

Brunt D (1932) Notes on radiation in the atmosphere. Q J R Meteorol Soc 58:389-420

Brutsaert W (eds) (1982) Evaporation into the atmosphere. Reidel, Dordrecht

Campbell GS, Norman JM (eds) (2000) An introduction to environmental biophysics. Springer, New York

Evans EC, McGregor GR, Petts GE (1998) River energy budgets with special reference to river bed processes. Hydrol Proc 12:575595, doi:10.1002/(SICI)1099-1085(19980330)12:4<575::AIDHYP595>3.0.CO;2-Y

Garratt JR (eds) (1992) The atmospheric boundary layer. Cambridge University Press, Cambridge

Huang J, Walker ED, Vulule J, Miller JR (2006) Daily temperature profiles in and around Western Kenyan larval habitats of Anopheles gambiae as related to egg mortality. Malar J 5:87, doi:10.1186/1475-2875-5-87

Iqbal M (eds) (1984) An introduction to solar radiation. Academic Press, New York

Jacobs AFG, Jetten TH, Lucassen DC, Heusinkveld BG, Nieveen JP (1997) Diurnal temperature fluctuations in a natural shallow water body. Agric For Meteorol 88:269-277, doi:10.1016/ S0168-1923(97)00039-7

Jacobs AFG, Heusinkveld BG, Nieveen JP (1998) Temperature behavior of a natural shallow water body during a summer 
period. Theor Appl Clim 59:121-127, doi:10.1007/ s007040050017

Jacobs CMJ, Kohsiek WIM, Oost WA (1999) Airsea fluxes and transfer velocity of $\mathrm{CO} 2$ over the North Sea: results from ASGAMAGE. Tellus B 51:629-641, doi:10.1034/j.16000889.1999.t01-2-00005.x

Jacobs AFG, Heusinkveld BG, Kraai A, Paaijmans KP (2008) Diurnal temperature fluctuations in an artificial small shallow water body. Int J Biometeorol 52:271-280, doi:10.1007/ s00484-007-0121-8

Jensen ME, Burman RD, Allen RG (eds) (1990) Evapotranspiration and Irrigation Water Requirements (ASCE Manuals and Reports on Engineering Practice). American Society of Civil Engineers, New York

Jepson WF, Moutia A, Courtois C (1947) The malaria problem in Mauritius: the bionomics of Mauritian anophelines. Bull Entomol Res 38:177-208

Losordo TM, Piedrahita RH (1991) Modelling temperature variation and thermal stratification in shallow aquaculture ponds. Ecol Model 54:189-226, doi:10.1016/0304-3800(91)90076-D

Lyimo EO, Takken W, Koella JC (1992) Effect of rearing temperature and larval density on larval survival, age at pupation and adult size of Anopheles gambiae. Entomol Exp Appl 63:265-271, doi:10.1007/BF00192775
Orlob GT (1983) Models for stratified impoundments. In: Biswas AK (ed) Models for Water Quality Management. McGraw-Hill, New York, pp 273-313

Paaijmans KP, Jacobs AFG, Takken W, Heusinkveld BG, Githeko AK, Dicke M, Holtslag AAM (2008a) Observations and model estimates of diurnal water temperature dynamics in mosquito breeding sites in western Kenya. Hydrol Proc (in press), doi:10.1002/hyp.7099

Paaijmans KP, Takken W, Githeko AK, Jacobs AFG (2008b) The effect of water turbidity on the near-surface water temperature of larval habitats of the malaria mosquito Anopheles gambiae. Int $\mathrm{J}$ Biometeorol (in press), doi:10.1007/s00484-008-0167-2

Service MW (eds) (1993) Mosquito ecology. Field sampling methods. Elsevier, London

Stull RB (eds) (2000) Meteorology for scientists and engineers. Brooks/Cole, Pacific Grove

Sutherst RW, Maywald GF, Skarrat DB (1995) Predicting insect distributions in a changed climate. In: Harrington R, Stork NE (eds) Insects in a changing environment. Academic Press, London, pp 59-91

Weast R (eds) (1984) CRC Handbook of chemistry and physics. A ready-reference book of chemical and physical data. Chemical Rubber Comp. Press, Cleveland

WHO (2005). World Malaria Report 2005. Geneva, World Health Organization 